\title{
Tensile properties of $\alpha$-titanium alloys at elevated temperatures
}

\author{
Authors: Tarik Nawaya ${ }^{1 *}$, Werner Beck ${ }^{2}$, Axel von Hehl ${ }^{1}$ \\ 1. Leibniz Institute for Materials Engineering IWT-Bremen, University of Bremen \\ 2. FormTech GmbH
}

* Corresponding Author: nawaya@iwt-bremen.de

\begin{abstract}
Hot-deep drawing is an innovative processing technology to produce complex shaped sheet metal components with constant wall thickness from high-strength lightweight materials. For some aerospace and automotive applications oxidation resistance at medium to high temperatures is an important aspect. In terms of this titanium $\alpha$-alloys are often used due to their balanced relation of strength and oxidation resistance. In the presented study the stress-strain characteristics of several $\alpha$-titanium alloys were determined at ambient and elevated temperatures by means of hot tensile tests. Besides the commercially pure Titanium alloy ASTM-Grade 4, two novel $\alpha$-titanium alloys were investigated. Regarding the hot forming properties a comparison with $\alpha-\beta$ Ti-6Al-4V alloy was conducted. The hot tensile tests were carried out by means of a particular forming dilatometer type "Gleeble 3500" at 400, 500, 600, 650, 700 and $800{ }^{\circ} \mathrm{C}$. The test showed favorable peak plasticity for all $\alpha$-alloys at the temperature range between 600 and $650{ }^{\circ} \mathrm{C}$ in contrast to lower or higher temperatures. All samples were metallographically characterized.
\end{abstract}

Key words: titanium $\alpha$-alloys, hot tensile properties, elevated temperatures, Gleeble 3500.

\section{Introduction}

Titanium alloys provide both a high absolute and a high density specific strength along with a good to excellent corrosion resistance at low but also at high temperatures. Their corrosion resistance raises their usage to manufacture chemical as well as biomedical components [1]. Basically, commercial pure titanium (CP) and $\alpha$-titanium alloys exhibit the best corrosion resistance upon the titanium family. However, these alloys are not able to be phase hardened owing to the lack of $\beta$ phase. For this reason, their application is wide spread in applications, such as medical implants, undersea stuff and sport goods, where high strength is not the major needed property, but enhanced juz7hcorrosion stability is mainly demanded [2,3]. Due to their high elastic energy at room temperature, $\alpha$-alloys are not cold formed in order to avoid the spring back. Hence, hot deep drawing becomes a novel method to manufacture titanium sheet metal of $\alpha$-alloys with minimized spring back potential. Since $\alpha$-alloys have a good responsivity to the stress relief [2], they are suitable for novel processing approaches like the so-called hot creep forming that is a hot deep drawing followed by a stress relief stage to prevent from spring back [4,5]. On the other hand, heating titanium sheets to a higher temperature causes the formation of detrimental $\alpha$-case in the surface layer by diffusion, which affects the late fatigue properties of the part tremendous. This has been studied in [6] and a statement about the best forming temperature for some $\alpha$ titanium alloys were made. Figure 1 shows an $\alpha$-case surface layer of the sheet metal depending on to the forming temperature.
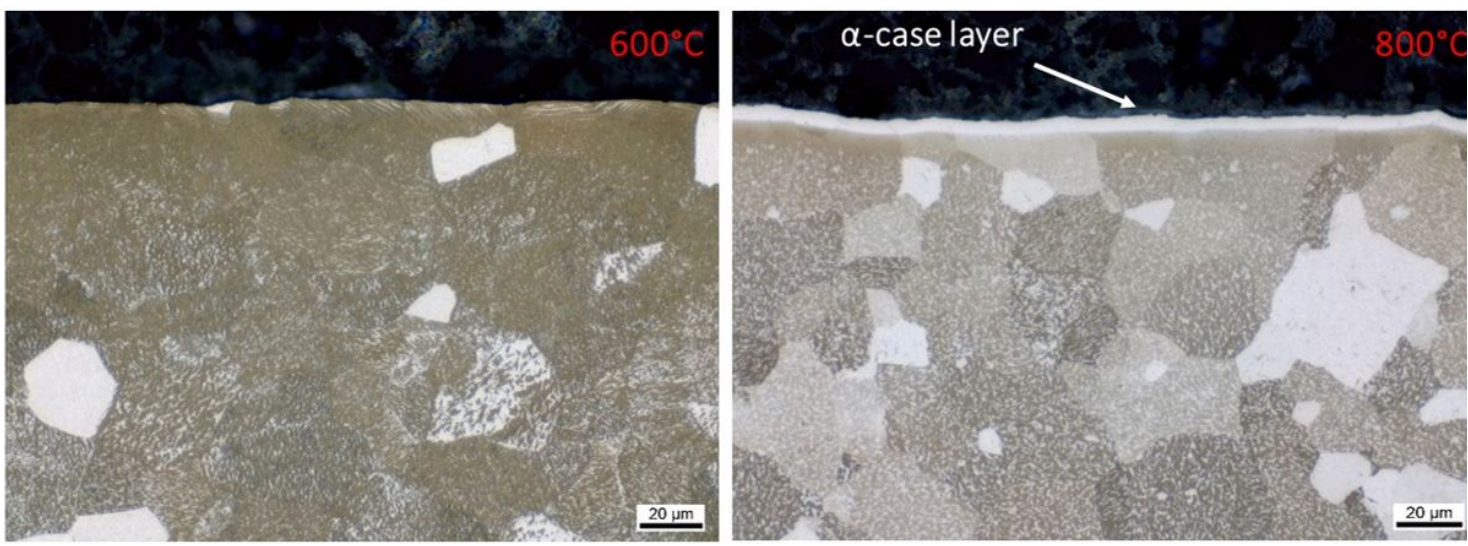
Figure 1: Formation of $\alpha$-case layer depending on the temperature, $600{ }^{\circ} \mathrm{C}$ (left), $800{ }^{\circ} \mathrm{C}$ (right).

Ti-6Al-4V as the most used titanium alloy [3] has replaced the CP titanium in such cases where high strength is required. The used alloying elements allow a strength increase by forming and heat treating. Even its response to the stress relief is stated to be perfect $[7,8]$. Compared to $\alpha$ alloys Ti-6Al-4V endures also higher application temperature, whereas aluminum enhances the oxidation resistance in addition.

\section{Motivations}

The focus of the presented study is on the investigation of the hot creep forming behavior of several titanium alloys. With regard to civilian airplane applications like T ducts for the air-bleed system [9] the deep-drawn sheet has to be laser weldable, why some $\alpha$-alloys were chosen to be investigated owing to their good weldability. The chemical composition of the considered alloys are listed in table 1. Besides the commercial pure titanium ASTM Grade 4, which is well-known e.g. in the medical area, alloy KS1.2ASNEX produced by Kobesteel ${ }^{\circledR}$ was investigated. Latter is regarded as superior alloy with respect to oxidation resistance compared to the ASTM Grade 2 [10]. However, KS1.2ASNEX exhibits higher yield strength and a minimal improvement in oxidation resistance. Newly, the alloy finds a usage in the aero engines as well as in the exhaust manufacture. As third alloy Exhaust-XT developed by TiMet ${ }^{\circledR}$ for automotive applications to produce exhaust components was also investigated. Finally, Ti$6 \mathrm{Al}-4 \mathrm{~V}$ serves within the study as reference alloy to assess the three aforementioned alloys.

Table 1: Chemical composition of the regarded alloys.

\begin{tabular}{|c|c|c|c|c|c|c|c|c|c|c|}
\hline & \multicolumn{10}{|c|}{ Mass- \% (max.) } \\
\hline & AL (\%) & $\mathrm{V}(\%)$ & $\mathrm{Nb}(\%)$ & Si (\%) & $\mathrm{Fe}(\%)$ & C (\%) & $O(\%)$ & $\mathrm{N}_{2}(\%)$ & $\mathrm{H}_{2}(\mathrm{ppm})$ & $\mathbf{T i}$ \\
\hline KS1.2ASNEX [10] & 0.7 & - & 0.3 & 0.6 & 0.2 & 0.08 & 0.15 & 0.05 & 13 & bal \\
\hline Exhaust XT [11] & - & - & - & 0.6 & 0.5 & 0.1 & 0.15 & 0.03 & 15 & bal \\
\hline ASTM-Gr.04 [12] & - & - & - & - & 0.5 & 0.08 & 0.4 & 0.05 & 12.5 & bal \\
\hline Ti-6Al-4V [13] & 6.75 & 4.5 & - & - & 0.4 & 0.08 & 0.2 & 0.05 & 15 & bal \\
\hline
\end{tabular}

Within the scope of optimization the parameter set of stress relaxation, it was necessary to find out the best forming temperature, in which hot creep forming achieves convenient hot deep drawing conditions and $\alpha$-case phenomenon can be avoided simultaneously. For this goal the stress strain behavior of the above mentioned alloys was investigated at different forming temperatures.

\section{Experimental procedure}

An uniaxial tensile test was conducted at seven temperature levels: Room temperature (RT), 400, 500, $600,650,700$ and $800{ }^{\circ} \mathrm{C}$. The temperature of $650{ }^{\circ} \mathrm{C}$ was chosen in consideration of results published in works of [6], who assumed that this temperature level is outside the critical $\alpha$-case formation.

Figure 2 depicts both types of the used tensile specimens. All the specimens were cut and tested in as-received condition and did not undergo any kind of prior heat treatment. The specimens tested at RT were cut according to Airbus standard QVA-Z10-38-00. The tensile tests at RT were conducted with a test machine of type Zwick-Roell with a clamping pressure of 1.5 bar. Strain gauges were applied in order to measure a uniform elongation, so that the elongation to fracture will be deduced out of the machine's traverse path. The thermal tension test at elevated temperatures was carried out by means of a servo-hydraulic dilatometer of type DSI Gleeble 3500, which enables an experimental hot-forming simulation under given time-temperature regimes by conductive heating and gas quenching. Owing to the laser extensometer set up in the machine, a strain measurement in two direction is possible. In order to perform the dimensional measurement an integrated pyrometer was used. A non-oxidation atmosphere was gained by an inert gas that has been applied inside the Gleeble test machine to avoid the detrimental superficial oxidation. The 
strain rate was kept constant at $25 \cdot 10^{-4} \mathrm{~s}^{-1}$ in all cases. Each test was repeated twice to confirm the results. In the results section only one representative curve will be shown respectively.
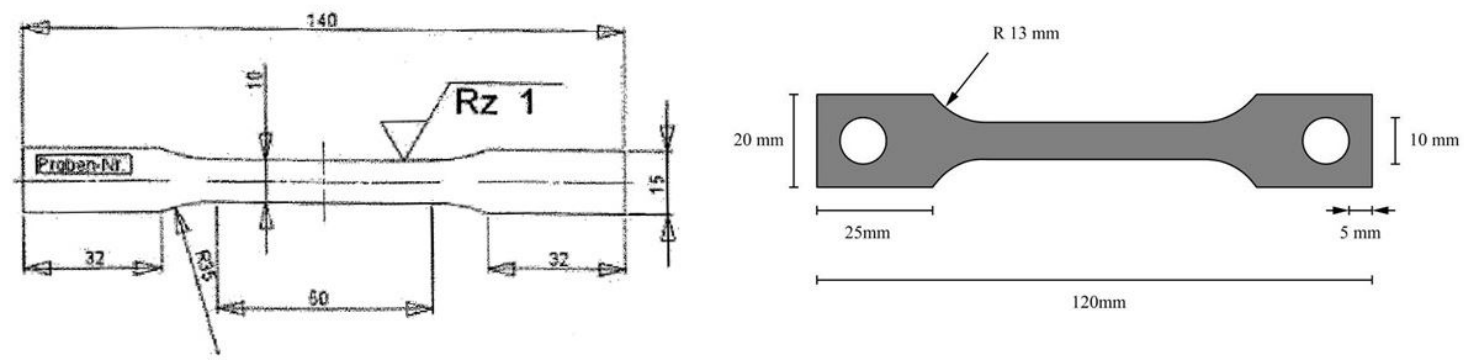

Figure 2: Specimens used in the approach, at room temperature (left) and at high temperatures (right)

After the tensile tests the experiments were accompanied by complementary investigations by means of light microscope, microprobe and electron back scattering diffraction (EBSD) to assess the results on microscale.

\section{Results}

Figure 3 shows the tensile curves of the concerned $\alpha$-alloys in comparison with alloy Ti-6Al-4V at room temperature. It is remarkable that alloy ASTM-Gr.04 exhibits the highest strength. A yield strength of $600 \mathrm{MPa}$ and a tensile strength of $700 \mathrm{MPa}$ were determined. Exhaust XT and KS1.2ASNEX have a tensile strength of $530 \mathrm{MPa}$ and $410 \mathrm{MPa}$ in a row. Comparing to the Ti$6 \mathrm{Al}-4 \mathrm{~V}$ these alloys present a less strength, whose tensile strength is about $900 \mathrm{MPa}$. On the other hand, it is remarkable that the ductility of all the regarded $\alpha$-alloys is better than the Ti-6Al-4V one. While the elongation to fracture of the $\alpha-\beta$ alloy amounts $12 \%$, it exceeds $25 \%$ in the case of the $\alpha$-alloys. However, forming handbooks recommend to focus on the area between the $0.2 \%$ strain and the uniform elongation, since beyond the latter it is hard to expect the behavior of the material anymore [14]. Based on this fact KS1.2ASNEX seems to be the most ductile alloy among the below depicted ones at RT characterizes by the widest area of plasticity. A distinct elastic limit is noticed for all alloys, which is typical for titanium alloys.

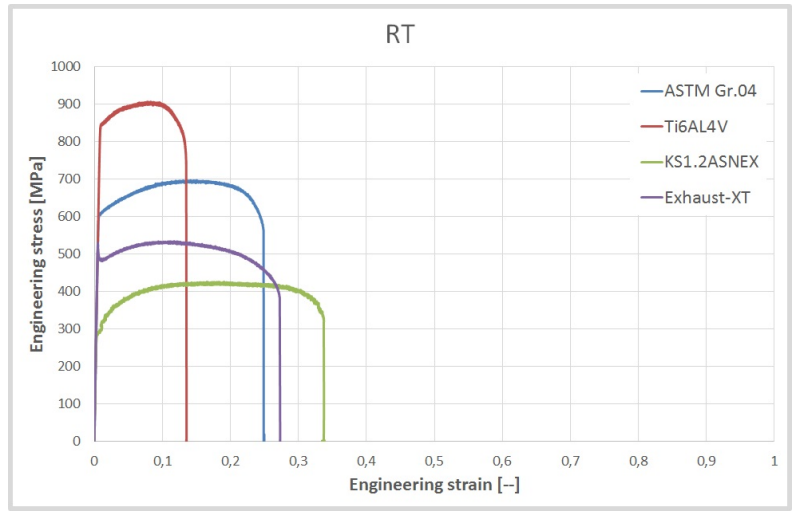

Figure 3: Stress-strain curve at room temperature.

With respect to the considered $\alpha$-alloys, a similar behavior at elevated temperatures is detected for all of them. As expected a material softening takes place, the higher the temperatures are. The yield strength ranges between 50 to $220 \mathrm{MPa}$ depending on the temperature range from $400{ }^{\circ} \mathrm{C}$ up to $800{ }^{\circ} \mathrm{C}$, whereby Exhaust XT tends to slightly higher strength values along the temperature range than KS1.2ASNEX. Table 2 listed the tensile properties at each temperature. All values stated in the table 2 were tested with test specimens taken in rolling direction. It is important to mention the typical anisotropic characteristics of titanium. Values in transverse direction are generally higher than those in rolling direction [15]. 
Table 2: Mechanical properties in each temperature.

\begin{tabular}{|c|c|c|c|c|c|c|c|c}
\hline \multirow{2}{*}{$\begin{array}{c}\left.\text { Temperature }{ }^{\circ}{ }^{\mathbf{C}}\right] / \text { Strength } \\
{[\mathbf{M P a}]}\end{array}$} & \multicolumn{2}{|c|}{ ASTM-Gr.04 } & \multicolumn{2}{c|}{ Exahust-XT } & \multicolumn{2}{c|}{ KS1.2ASNEX } & \multicolumn{2}{c}{ Ti-6AI-4V } \\
\cline { 2 - 11 } & YS & US & YS & US & YS & US & YS & US \\
\hline RT & 600 & 700 & 500 & 530 & 300 & 405 & 850 & 905 \\
\hline 400 & 175 & 225 & 225 & 310 & 150 & 250 & 600 & 700 \\
\hline 500 & 160 & 200 & 190 & 300 & 130 & 230 & 520 & 650 \\
\hline 600 & 120 & 160 & 140 & 180 & 100 & 200 & 440 & 470 \\
\hline 650 & 80 & 110 & 130 & 140 & 90 & 160 & 360 & 380 \\
\hline
\end{tabular}

Regarding the formability, an ascending plasticity with increasing temperature was expected before conducting the experiments. However, according to the results of the stress-strain curves shown in the in the three diagrams in figure 4 the materials at $500{ }^{\circ} \mathrm{C}$ become less ductile than at $400{ }^{\circ} \mathrm{C}$. In addition, the material at $700{ }^{\circ} \mathrm{C}$ as well as at $800{ }^{\circ} \mathrm{C}$ does not exhibit any strain hardening in the plastic region independent from the material. Consequently, the materials become more easily formable, though, but present a minimal ductility with an elongation to fracture of only $10 \%$.

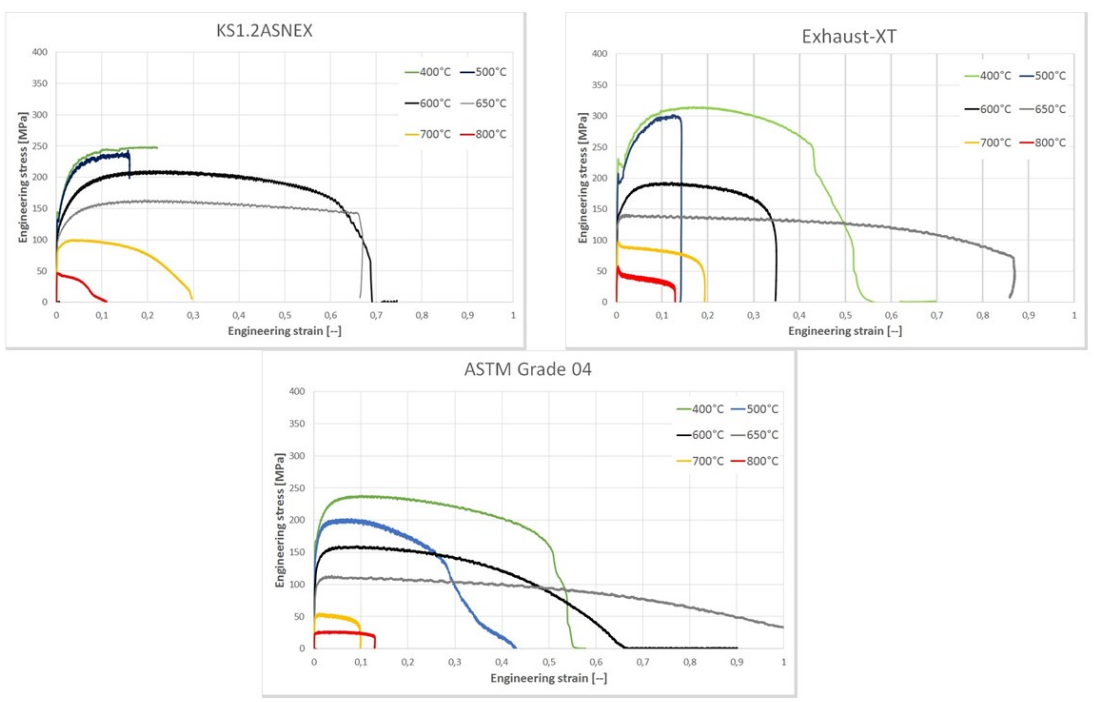

Figure 4: Stress-Strain curves at elevated temperatures.

As can be seen over the diagrams, the best results among these experiments were achieved at $650{ }^{\circ} \mathrm{C}$. At this temperature level a compromise between the undesired softness and the high ductility can be ensured. Especially in KS1.2ASNEX the elongation to fracture amounts nearly $70 \%$ and the plasticity region is also convenient, figure 4.a. The other two alloys demonstrate an excellent ductility at $650{ }^{\circ} \mathrm{C}$ as well. Their plasticity region is wider at $600{ }^{\circ} \mathrm{C}$, though.

In figure 5 the curves of the thermal tension test at $600{ }^{\circ} \mathrm{C}$ as well as at $650{ }^{\circ} \mathrm{C}$ for the regarded $\alpha$-alloys are depicted in comparison with the curves of Ti-6Al-4V. This $\alpha-\beta$ alloy obtains obviously the highest tensile strength irrespective of the test temperature. Its tensile strength ranges between $470 \mathrm{MPa}$ at $600{ }^{\circ} \mathrm{C}$ and $400 \mathrm{MPa}$ at $650{ }^{\circ} \mathrm{C}$. However, the plastic region is still narrow. On the contrary, $\alpha$-alloys proves at this temperature range higher ductility than the Ti-6Al-4V. The tensile behavior of KS1.2ASNEX demonstrates a very good plasticity comparing to the other two $\alpha$-alloys, with an elongation to fracture of $65 \%$ at $600{ }^{\circ} \mathrm{C}$ and $650{ }^{\circ} \mathrm{C}$. While ASTM Grade 04 reveals the highest strength among $\alpha$-alloys at room temperature, the difference diminishes at elevated temperatures. Even more, the ASTM Grade 04 shows at both elevated temperatures a slightly lower strength compared to the other two $\alpha$-alloys, whose strength is still less than half of that of the Ti-6Al-4V anyway. In general, it is noticeable that the ultimate strength at $600^{\circ} \mathrm{C}$ is lower of half of it at room temperature. 

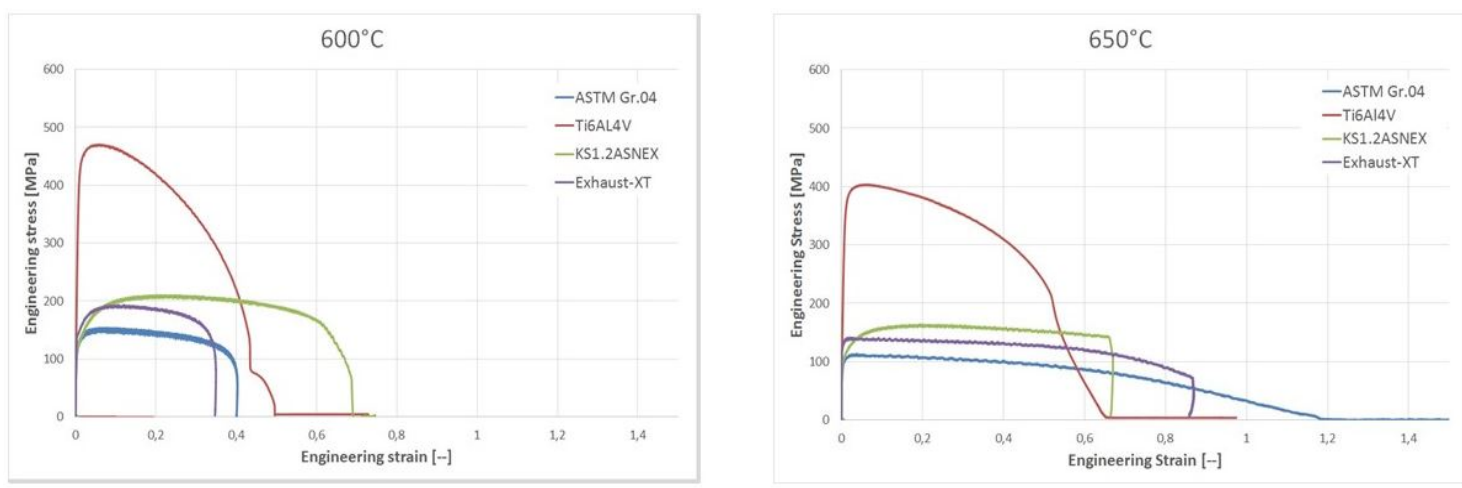

Figure 5: Stress-strain curves at favorable temperatures for the four alloys.

\section{Discussion}

In this section some investigations are depicted to illustrate the phenomena emerged within the results. Since the results obtained from Ti-6Al-4V within our approach reveal a similar perspective to those published in [20, 21], a discussion about Ti-6Al-4V was waived. The major focus of the discussion is on KS1.2ASNEX due to its best tensile behavior at target temperature of $650{ }^{\circ} \mathrm{C}$. Table 3 presents the evolution of the grain size of the microstructure from RT up to $800^{\circ} \mathrm{C}$.

Table 3: Grain-size index and anisotropy R-Value of $\alpha$-alloys.

\begin{tabular}{|c|c|c|c|}
\hline \multirow{2}{*}{ Temperature $\left[^{\circ} \mathbf{C}\right]$} & \multicolumn{3}{|c|}{ G index / R-Value } \\
\cline { 2 - 4 } & ASTM-Gr.04 & Exhaust-XT & KS1.2ASNEX \\
\hline RT & 8 & 11 & 7.5 \\
\hline 600 & $7 / 0.72$ & $10 / 1.39$ & $8 / 0.95$ \\
\hline 800 & 6.5 & 9.5 & 9 \\
\hline
\end{tabular}

The microstructure at RT can be considered as fine-grained. Its G-index ranges between 7.5 for KS1.2ASNEX and 11 for Exhaust-XT. According to the standard for grain size investigation ISO 643 an index of 6 and more indicates a fine microstructure with good mechanical properties. At $600{ }^{\circ} \mathrm{C} \mathrm{KS1.2ASNEX} \mathrm{exhibits} \mathrm{a} \mathrm{refinement} \mathrm{in} \mathrm{the} \mathrm{structure} \mathrm{characterized} \mathrm{by}$ an increase of the $\mathrm{G}$ index from 7.5 to 8 contrary to the Exhaust-XT, which exhibits coarsening (decrease of the $\mathrm{G}$ index from 11 to 10). However, this grain size index is still in the area of fine-grain, even at $800{ }^{\circ} \mathrm{C}$ with $\mathrm{G}=9.5$. These results could imply why Exhaust-XT and KS1.2ASNEX exhibit a similar tensile behavior at elevated temperatures, while XT-Exhaust a higher strength at room temperature. Figure 6 depicts micrographs showing the aspect of the microstructure of each alloy at RT as well as $600{ }^{\circ} \mathrm{C}$. All micrographs show an equiaxed grain distribution and prove that there no twinning has occurred. The authors of [23] claim a dependency between oxygen content and the relation c/a of lattice parameters that causes a suppression of twinning with increasing oxygen content. Hence, the decrease of ductility of ASTM-Gr.04 compared to other $\alpha$-alloys may be attributed to the higher oxygen content $[22,23]$. 


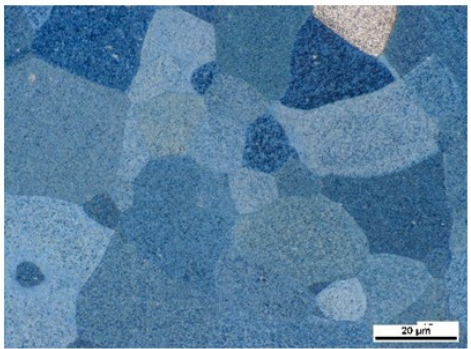

6. a: KS1.2ASNEX, RT.

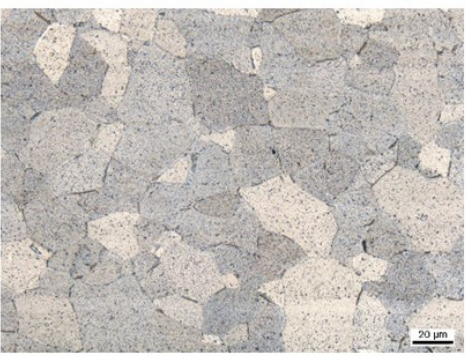

6. d: KS1.2ASNEX, $600{ }^{\circ} \mathrm{C}$

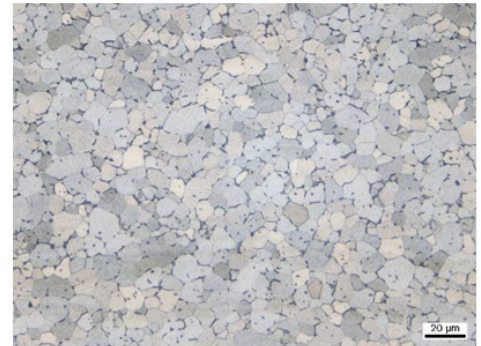

6. b: Exhaust-XT, RT.

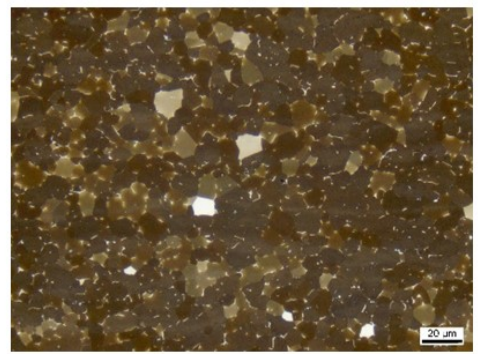

6. e: Exhaust-XT, $600{ }^{\circ} \mathrm{C}$.

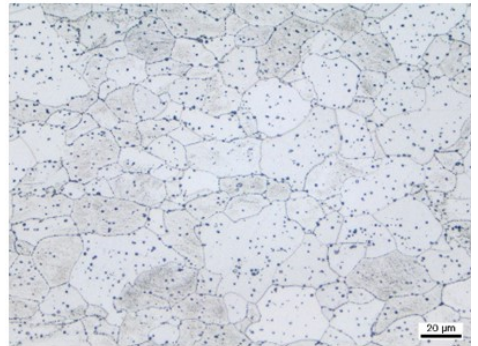

6. c: ASTM-Gr.04, RT

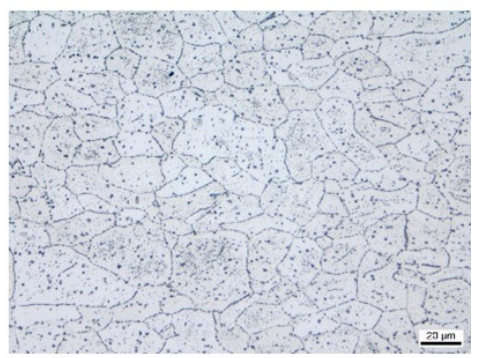

6. f: ASTM-GR. $04,600{ }^{\circ} \mathrm{C}$.

Figure 6: Optical micrographs of $\alpha$-alloys.

The proportional increase in ductility with temperature can be also traced back to an increase in strain rate sensitivity, whereas the strain hardening decreases obviously in high temperatures $[16,17]$. However, the observed $\alpha$-alloys in this study belong to those with anisotropic properties, which affects the ductility at higher temperatures more than at RT [18], owing to the higher R-values obtained at each temperature level. These values are lower for ASTM-Gr.04 than for KS1.2ASNEX at high temperatures and, thus, results in a higher ductility for the latter alloy at elevated temperatures, see table 3.

Additional alloying elements would let expect impact the mechanical Properties. As can be seen in table 1, KS1.2ASNEX is the only one among the $\alpha$-alloys which is alloyed with $\mathrm{Al}$ and $\mathrm{Nb}$. However, low percentage is not sufficient to reduce softening of the material noticeably undergoing the aforementioned temperatures [24]. The effect of $\mathrm{Fe}$ on the mechanical properties can also be neglected owing to its lower content than 3\%, which is considered as a minimum content to impact the material behavior [21]. On the other hand, both exhaust alloys contain a tiny Si content. Precipitations of latter are illustrious of embrittlement at higher temperatures [19].

For this purpose, an EDX mapping was carried out to investigate the distribution of silicides in the specimens after undergoing high temperatures. According the results in figure 7 for $\mathrm{KS} 1.2 \mathrm{ASNEX}$, there are some silicides precipitated at $400{ }^{\circ} \mathrm{C}$ and 500 ${ }^{\circ} \mathrm{C}$. Unfortunately, it was not possible to specify the type of the formed silicide as well as the location of their formation. However, in figure 7 higher precipitation ratio of $\mathrm{Si}$ at $500{ }^{\circ} \mathrm{C}$ in comparison to $400{ }^{\circ} \mathrm{C}$ is indicated, which can be the main reason of being the material less ductile at $500{ }^{\circ} \mathrm{C}$. A formation of $\mathrm{Ti}_{5} \mathrm{Si}_{3}$ or other type of particles cannot be confirmed. The backscattering technique express the mean value of the element distribution along the specimen. Figure 7 presents a backscattering micrograph. In case of Si distribution it seems to be at both temperatures identical. Due to the EDX-mapping the amount of $\mathrm{Si}$ in some pellets were observed. The highlighted white point at $500{ }^{\circ} \mathrm{C}$ includes about $6.5 \%$ of $\mathrm{Si}$, while at $400{ }^{\circ} \mathrm{C}$ a maximum content of $3.5 \%$ were detected. 

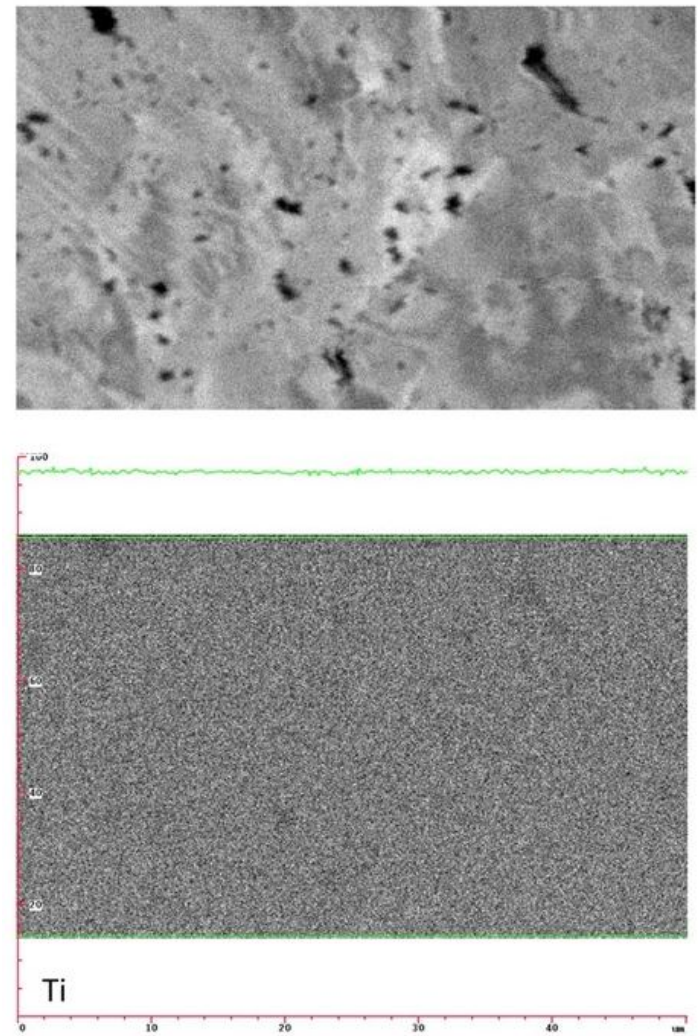
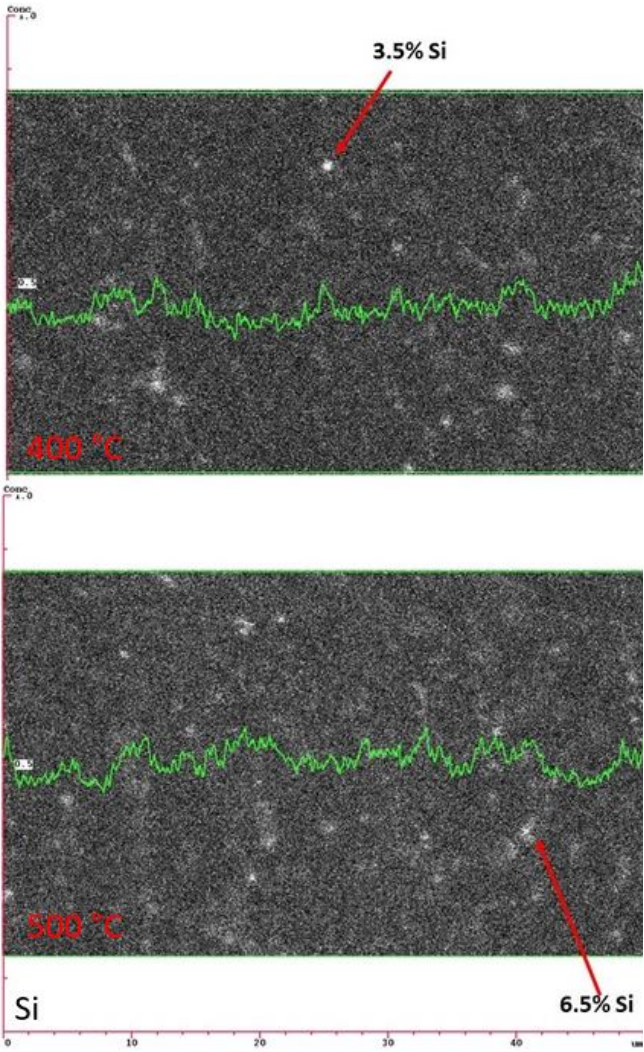

si $-\mathrm{sum}$

Figure 7: Backscattering test and element distribution of Si.

\section{Conclusion}

The focus of the presented work was the investigation of the stress-strain behavior at elevated temperatures of three $\alpha$-titanium alloys, namely ASTM-Gr.04, Exhaust-XT and KS1.2ASNEX. It aimed a determination of the best forming temperature, at which the material manifests a convenient strength with superior ductility. Following conclusions can be made:

- ASTM-Gr.04 owns the higher strength at room temperature. This could be attributed to the higher content of oxygen compared to the other two alloys.

- All three alloys exhibit a softening starting at $700{ }^{\circ} \mathrm{C}$, resulting in a lack of strain hardening and making the forming at this temperature unfavorable owing to the reduction of elongation.

- At $500{ }^{\circ} \mathrm{C}$ the three alloys become less ductile than expected. Precipitation of silicides at this temperature is assigned to be the main reason of the material brittleness in this temperature range.

All investigated $\alpha$-alloys reveal a more favorable stress-strain behavior at elevated forming temperatures than the reference alloy Ti-6Al-4V and point out their high application potential for novel hot-deep drawing approaches. 


\section{Outlook}

- The backscattering test shows quantitatively the formation of silicides precipitation. However, the substance of such particles as well as their location is a matter to be considered by means of the scanning electron microscope.

- The effect of applying a protective gas is to be considered more deeply.

\section{Acknowledgements}

- The research project „TiB-Air“ (20W1522E) was funded by the German Federal Ministry for Economic Affairs and Energy (BMWi) due to a resolution of the Deutscher Bundestag within the "Luftfahrtforschungsprogramm 5-2". The authors are grateful for the financial support.

- The authors would also like to thank Dr.-Ing. Münip Dalgic, Bremen Institute for Materials Testing (MPA), for conducting the hot tensile test.

\section{References}

[1] C. Leyens, M.Peters, Titanium and Titanium Alloys, fundamentals and applications. Willey-VCH Verlag (2006).

[2] M.J. Donachie, Titanium Guide. $2^{\text {nd }}$ edition, AMS international, (2000) 13-24.

[3] G. Lütjering, J.C. Williams, Titanium. $2^{\text {nd }}$ edition. Springer Verlag, (2007) 19.

[4] L. Po, Z. Yingying, S. Debin and G. Bin, Study on load relaxation based on hot bending and sizing of Ti-6Al-4V alloy sheet, AIP conference proceeding (2013). 1532, 317-323.

[5] F.Ozturk, R.E. Ece, N. Polat, A. Koksal, Effect of warm temperature on springback compensation of titanium sheet. Material and manufacturing process, (2010). 25:9, 1021-1024.

[6] T. Nawaya, A. von Hehl, S. Wagner, W. Beck, Hot deep drawing processing of titanium sheet metal parts for high temperature applications. Advanced Engineering Materials, Oct. (2018).

[7] J. Xiao, D. sheng LI, P. DING, K. ZHAO, X. HUANG, M. XU, Process parameters optimization of Ti-6Al-4V alloy sheet during hot stretch-creep forming. Transactions of nonferrous metals society of China (2015), Vol.25, Issue 2, 420-428.

[8] P. Liu, Y. Zong, D. Shan, B. Guo, Relationship between constant-load creep, decreasing-load creep and stress relaxation of titanium alloy. Materials Science \& Engineering A 638 (2015) 106-113.

[9] FormTech: http://www.formtech.de/download/formtech-praesentation.pdf. Published on 6th/15/2015.

[10] KOBE STEEL, L. Kobe Steel, LTD. Proprietary information. Kobelco, (2005).

[11] TIMETAL $®$ Exhaust XT TM, datasheet (2006).

[12] Thyssenkrupp Materials Schweiz, datasheet (2010).

[13] TIMETAL ${ }^{\circledR}$ 6-4, 6-4 ELI \& 6-4-.1Ru, datasheet (2000).

[14] E. Doege, B. Behrens, Handbook „Umformtechnik“, $2^{\text {nd }}$ edition, Springer Verlag (2010) 259-264.

[15] S. Suwas, R. K. Ray, Crystallographic texture of materials, Engineering Materials and Processes, Springer Verlag (2014).

[16] N. Itoh, M. Ogaya, S. Ishiyamai, T. Matsushita, Y. Hayashi, M. Koike, J.Joetsu, The press formability of commercial pure titanium at warm working temperature, in: Titanium80 Sci. Technol. Proc. Fourth Int. Conf. Titan. Metall. Soc. AIME, Metallurgical Society of AIME, Kyoto, Japan, (1980) 2523.

[17] A. Seeger, J. Diehl, S. Mader, H. Rebstock, Work-hardening and worksoftening of face-centred cubic metal crystals, Philos. Mag. 2 (1957) 323-350.

[18] A. Caballero, F. Li, D. Ojos, M. Atkinson, J. da Fonseca, On the ductility of alpha titanium: the effect of temperature and deformation mode, Acta Materialai, (2018).

[19] W. Jia, W. Zeng, H. Yu, Effect of aging on the tensile properties and microstructures of a near-alpha titanium alloy, Materials and Design 58 (2014) 108-115.

[20] S. Kumar, K. Chattopadhyay, V. Singh, Tensile behavior of Ti-6Al-4V alloy at elevated temperatures, Proceeding the international conference on multifunctional materials, structure and applications (2014).

[21] O. Kanou, N. Fukada, M. Hayakawa, The effect of Fe addition on the mechanical properties of Ti-6Al-4V alloys produced by the prealloyed powder method, Materials Transactions, Vol. 57, No. 5 (2016) 681-685. 
[22] M.C. Brandes, M. Baughman, M.J. Mills, J.C. Williams, The effect of oxygen and stress state on the yield behavior of commercially pure titanium, Materials Science and Engineering A 551 (2012) 13-18.

[23] D. Kang, K. Lee, E. Kwon, T. Tsuchiyama, Variation of work hardening rate by oxygen contents in pure titanium alloy, Materials Science \& Engineering A 632 (2015) 120-126.

[24] B. Fu, H. Wang, C. Zou, Z. Wie, The effect of Nb content on microstructure and fracture behavior of near $\alpha$ titanium alloys, Materials and Design 66 (2015) 267-273. 